\title{
Phytochemical Screening, Chemical Constituents, Traditional Medicine Usage, Pharmacological Effect, Metabolism and Pharmacokinetics of Semen armeniacae
}

\author{
Khaled Mohamed Mohamed Koriem 1,*(D) \\ 1 Department of Medical Physiology, Medical Research Division, National Research Centre, 33 El-Buhouth Street, Dokki, \\ Cairo, 12622, Egypt \\ * Correspondence: kkoriem@yahoo.com (K.M.M.K.)
}

Scopus Author ID 24477156100

Received: 21.04.2021; Revised: 19.06.2021; Accepted: 23.06.2021; Published: 8.08.2021

\begin{abstract}
Semen armeniacae refers to the seeds of Prunus armeniaca L. (Rosaceae). The Prunus armeniaca L. plant is spreading in the Korean peninsula, China, India, Japan, North Africa, and the United States of America. The Prunus armeniaca contains 3\% amygdalin, titratable acidity, sugars (saccharose, fructose, and glucose), and organic acids (citric and malic acids) in addition to prunasin and mandelonitrile. Semen armeniacae is used for the treatment of asthma and cough (with expectoration and fever). It is used in constipation therapy. It is also used as eardrops for inflammation and tinnitus and the treatment of skin diseases. The pharmacological effect of Semen armeniacae includes experimental and clinical pharmacology. Experimental pharmacology includes anticholinesterase, neuroprotective, analgesic, antipyretic, antitumor, antibacterial, antimicrobial, antifungal, and antitussive activities. Decoction of Semen armeniacae to 2275 patients with COVID-19 improves clinical parameters such as lung state, clinical cure rate, number of cough reduction cases, symptom score of cough, viral nucleic acid testing, and inflammatory biomarkers. Oral intake of Semen armeniacae extract for 28 days did not cause any hematological, biochemical, or histological changes in rats. The Prunus armeniaca plant declines oxidative stress, inflammation, fat degeneration, and necrosis in alcohol-induced in-vivo and in-vitro liver injury models. There is no effect on fertility in rats after eating Semen armeniacae for 5 weeks. The average daily dose $=3-9 \mathrm{~g}$ of Semen armeniacae rinsing in boiling water then adding to a decoction. In conclusion, Semen armeniacae has anticholinesterase, neuroprotective, analgesic, antipyretic, antitumor, antibacterial, antimicrobial, antifungal, and antitussive activities.
\end{abstract}

Keywords: Semen armeniacae; Prunus armeniaca; Rosaceae; medicine; toxicology; dose.

(C) 2021 by the authors. This article is an open-access article distributed under the terms and conditions of the Creative Commons Attribution (CC BY) license (https://creativecommons.org/licenses/by/4.0/).

\section{Introduction}

Semen armeniacae consists of the seeds of Prunus armeniaca L. (Rosaceae) [1-3]. Other names of Semen armeniacae include Abricotier, anzu, apricot, barqouq, chuli, cuari, culu, Himalayan wild apricot, touffah armani, wild apricot, and zardalou, [4,5]. The Prunus armeniaca L. plant is spreading in the Korean peninsula, China, India and Japan [6, 7]. The Prunus armeniaca L. plant is cultivated in North Africa, Asia and the United States of America [8]. The Prunus armeniaca L. plant is a medium-sized, deciduous tree with glabrous twigs and reddish bark. The plant leaves convoluted in the bud, blade broadly ovate, $5-7 \mathrm{~cm}$ long, $4-5 \mathrm{~cm}$ wide, acuminate, crenate-glandular. The plant petiole $=2.5 \mathrm{~cm}$ long, glandular; stipules, lanceolate, glandular on the margins. The plant flowers looking bisexual and pinky in color, 
solitary or fascicled, pedicels very short; calyx-tube campanulate, puberulent, $5 \mathrm{~mm}$ long; surrounding lobes, pubescent; petals sub-orbicular, 7-13 mm long; stamens inserted with the petals at the mouth of the calyx-tube; ovary and base of the style hairy. The plant fruit is a downy or glabrous, yellow-tinged, red drupe with a fleshy outer layer surrounding a hard stone containing the seed [7, 8]. The plant seeds (1.1-1.9 cm long, 0.8-1.5 cm wide, $0.4-0.8 \mathrm{~cm}$ thick) are flattened and plump. The plant seeds coat is yellowish-brown to deep brown with many deep-brown veins $[1,3]$. The Prunus armeniaca plant is used as an additive in manufacturing metallic nanoparticles, antioxidant agents, tissue culture media, binding agents in tablets, corrosion inhibitors, and as an additive in many foods and pharmaceutical industries [9]. The Prunus armeniaca plant is a Mediterranean fruit that has high fruit quality. It possesses a higher quantity of polyphenol compounds. The genes that occurred in the transcription of the plant phenolic compounds are ParFLS1, ParPAL1, ParDFR, ParPAL2, and ParFLS2 genes [10]. In the early stages of fruit development of Prunus armeniaca plant, the prunasin glycosides constituent level increased then decreased significantly; however, the amygdalin glycosides constituent level of the plant is present in small amounts lower than the prunasin glycosides constituent level. Then, at the late stages of plant fruit maturation, prunasin glycosides constituent level declined to zero, while amygdalin glycosides constituent increased linearly to be higher than the prunasin glycosides constituent level, then decreased or increased slowly until full maturity [11]. There are 10 bacterial strains isolated from Prunus armeniaca plant (leaves and fruits) in Montenegro and identified as Xap- causal agent of bacterial leaf spot and canker of stone fruits. All these strains induced hypersensitive reactions in tobacco leaves [12]. The Prunus armeniaca plant and Ephedrae Herba alleviate airway epithelial injury in asthmatic rats [13]. Gum Arabic-coated Prunus armeniaca declined weight loss, disease incidence, malondialdehyde level, and hydrogen peroxide. It caused higher total phenols, ascorbic acid, and antioxidant activity of the plant. It inhibited pectin methylesterase, cellulase, and polygalacturonase activity compared with the non-coated plant fruit. It contained higher levels of ascorbate peroxidase, peroxidase, catalase, and superoxide dismutase enzyme activities. It had better sensory and overall eating quality compared to the control Prunus armeniaca fruit. So, gum Arabic is a suitable edible coating for the quality conservation of Prunus armeniaca fruit [14]. There are correlations among carotenoid accumulation, plastid characteristics, and gene transcription in Prunus species [15].

This review aims to focus on the phytochemical screening, chemical constituents, traditional medicine usage, pharmacological effect, metabolism, and pharmacokinetics of Semen armeniacae.

\section{Semen armeniacae Chemical Constituents}

The Prunus armeniaca contains 3\% amygdalin glycoside ingredient detected by the method include silver nitrate [3] or by using the high-performance liquid chromatography [16]. The Prunus armeniaca contains soluble solids, titratable acidity, sugars (saccharose, fructose, and glucose), and organic acids (citric and malic acids). There are 33 volatile compounds, including 6 esters, 5 C6 compounds, 4 alcohols, 3 carbonyl compounds, 6 terpenic compounds, and 9 lactones in the plant [17]. The fruits of Prunus armeniaca contains 2 flavonoid glycosides (4',5,7-trihydroxy flavone-7-O-[beta-D-mannopyranosyl- $\beta$-D-allopyranoside and 3,4',5,7tetrahydroxy-3',5'-di-methoxy flavone 3-O-[alpha-L-rhamnopyranosyl- $\beta$-D-galactopyranoside) [18]. The Prunus armeniaca plant contains carotenoids such as trans- $\beta$-carotene and its $c i s$-isomers. The lutein was present also. It also contains $\beta$-cryptoxanthin linoleate, 
linolenate, and stearate. The Prunus armeniaca plant contains fatty acids such as linoleic (up to $47 \%$ ), palmitic (up to $32.7 \%$ ), and linolenic (up to 17.16\%) [19]. There are 13 carotenoids detected in the plant, as $\varepsilon$-carotene, $\alpha$-cryptoxanthin, and apocarotenal were newly detected carotenoids [20].

\section{Semen armeniacae Major Chemical Constituents}

Amygdalin represents major constituents (> 4.9\%). Other constituents are prunasin and mandelonitrile. The amygdalin-hydrolyzing enzyme, emulsion, and fatty acids, and sitosterols are found in the Prunus armeniaca plant [21]. The main components of Prunus armeniaca fruits were $\beta$-carotene and (E/Z)-phytoene, followed by $\beta$-cryptoxanthin and lutein [20]. The Prunus armeniaca L. kernel extract contains 6 diacylglycerols and 18 triacylglycerols with the predominance of dilinoleyl-olein, dioleoyl-linolein, and triolein, with percentages ranging from 19.0-32.8\%, 20.3-23.6\%, and 12.1-20.1\%, respectively. The Prunus armeniaca plant contains fatty acid (the lowest percentage of linoleic acid while the highest amount (higher than 60\%) of oleic acid). The Prunus armeniaca plant also contains coumarin derivative and amygdalin [22]. The Prunus armeniaca plant contains sucrose (32.94-42.49\%), malic acid (69.21$76.75 \%$ ), and quercetin-3-rutinoside (72.84-74.05\%). The Prunus armeniaca plant contains also 1-octen-3-ol, 1-dodecanol, pentanal, hexanal, (E)-2-hexenal, (E)-2-heptenal, 6-methyl-5hepten-2-one, (E)-2-nonenal, 1-octen-3-one, $\beta$-myrcene, and linalool [23].

\section{Semen armeniacae Traditional Medicine Usage}

Semen armeniacae is used as a decoction by dipping in boiling water and stir-frying until yellow [3]. It is applied for symptomatic treatment of asthma, cough with profuse expectoration, and fever. The seed oil is used for the treatment of constipation [3]. The seed oil is also used in the form of eardrops for inflammation and tinnitus and the treatment of skin diseases [24]. The Prunus armeniaca plant is used in Iranian traditional medicine to treat loss of memory [25]. The Prunus armeniaca plant improves human nutrition and health. At the same time, this plant represents an important source of many secondary metabolites that decline the risk of different diseases [26]. The administration of Prunus armeniaca attenuated bleomycin-induced pulmonary fibrosis, and consequently, this plant is effective in resisting oxidative damage and histopathologic lesion, serving a protection role on bleomycin-induced pulmonary fibrosis [27]. The Prunus armeniaca plant is also used to treat fatty liver diseases [28].

\section{Pharmacology of Semen armeniacae}

\subsection{Experimental pharmacology.}

5.1.1. Anti-cholinesterase and neuroprotective activities.

The water extract of Prunus armeniaca plant has a decreasing effect on the cholinesterase enzymes (acetyl- and butyryl-cholinesterase). At the same time, the water extract of Prunus armeniaca plant has neuroprotectivity [25]. The oil obtained from the leaves of Prunus armeniaca possesses acetylcholinesterase decreasing effect due to oil antioxidant effect [29]. The memory injury was amended by Prunus armeniaca plant. Also, the increased 
pyknosis, decreased dendritic arborization, and increased Hoechst-positive neurons in the hippocampal area were amended by Prunus armeniaca plant [30].

\subsubsection{Analgesic and antipyretic activities.}

The intake of $46 \mathrm{mg} / \mathrm{kg}$ of amygdalin to rats caused a small increase in body temperature and prevented ephedrine-induced hyperthermia [31]. In the hot plate and acetic acid-induced writhing tests in mice, the analgesic doses were $457 \mathrm{mg} / \mathrm{kg}$ and $288 \mathrm{mg} / \mathrm{kg}$. These 2 doses of amygdalin could not relieve withdrawal syndrome [32]. The analgesic effect of Prunus armeniaca is similar in its effect to Cupressus sempervirens in its effect [33]. The amygdalin in Prunus armeniaca plant is effective at alleviating inflammatory pain. It is used as an analgesic with anti-nociceptive and anti-inflammatory activities [34]. The Prunus species showed remarkable anti-inflammatory and antioxidant activities [35].

\subsubsection{Antitumor activity.}

Amygdalin administration to mice with P388 lymphocytic leukemia or P815 mast-cell leukemia has antitumor activity [36]. The most common herb used as complementary and alternative medicines in cancer patients to decrease chemotherapy-induced constipation is the Prunus armeniaca plant [37]. The antitumor effect of amygdalin is explained by increasing the expression of Bax (pro-apoptotic protein) and caspase-3 and decreasing the expression of Bcl2 (anti-apoptotic protein). Amygdalin increases the slowing of the cell cycle by blocking cell proliferation and growth [38]. The Prunus armeniaca ethanol extract and amygdalin inhibited tumor cell growth in a dose- and time-dependent way. This extract facilitates apoptosis induction in pancreatic cancer cells by a mitochondria-dependent pathway [39].

\subsubsection{Antibacterial, antimicrobial and antifungal activities.}

The Prunus armeniaca plant has antimicrobial effects against Listeria monocytogenes of the chitosan films [40]. The Prunus armeniaca possesses antimicrobial, antitubercular, anticancer, antimutagenic, antioxidant, cardioprotective, and antileishmanial activities [41]. The Prunus armeniaca L. has antimicrobial and antifungal effects [42]. The Prunus armeniaca L. possesses antiviral activity [43]. The Prunus armeniaca displays antibacterial activity [44]. The Prunus armeniaca plant possesses Xap as a causal agent with an antibacterial effect [45]. The Prunus armeniaca is a rich source of compounds that combat pathogenic bacteria and reduce the development of antibiotic resistance [46].

\subsubsection{Antitussive activity.}

Amygdalin $(30 \mathrm{mg}$ ) had antitussive effects in the sulfur dioxide gas-induced cough model in mice $[47,48]$. The enzymes (amygdalase and prunase) with gastric juice hydrolyze amygdalin to form few quantities of hydrocyanic acid, which stimulates the respiratory tract and causing antitussive and antiasthmatic effects [32]. Amygdalin produces a dose-dependent antitussive effect in guinea pigs and reduced hyperthermic syndrome induced by liposaccharides in rats. It blocked the bronchial contraction induced by acetylcholine/histamine. Amygdalin oral intake for 28 days did not cause any hematological, biochemical or histological changes in rats [49]. Amygdalin intake declined serum interleukin6 and tumor necrosis factor- $\alpha$ level in liposaccharide-injected mice. Amygdalin declined 
liposaccharide-caused interleukin- 6 and tumor necrosis factor- $\alpha$ levels in macrophages at the transcriptional level [50].

\subsection{Clinical pharmacology.}

Prunus armeniaca $L$. seed extract and its amygdalin constituent stimulate the apoptotic process by up-regulating caspase- 3 expression and down-regulating Bcl-2 expression. They also reduced vascular endothelial growth factor and Proliferating cell nuclear antigen levels and increased the antioxidant defense system. Moreover, AE and ACF treatments also inhibited human liver cancer cell lines and Ehrlich-Lettre ascites carcinoma cell proliferation and upregulated Beclin-1 expression [51]. Amygdalin has a tumor-preventive effect due to its is hydrolyzed to benzaldehyde, glucose, and cyanide inside the human body [52]. Amygdalin possesses anti-inflammatory, antibacterial, antioxidative, and immunoregulatory effects. Amygdalin has an antitumor effect in solid tumors such as bladder cancer, lung cancer, and renal cell carcinoma by causing apoptosis and cytotoxicity, stopping the cell cycle, and controlling the immune system [53]. Amygdalin is used in clinical applications as an antifibrotic, analgesic, immunomodulatory, antitumor, anti-inflammatory, anti-atherosclerosis, amending digestive system and reproductive system, improving neurodegeneration and myocardial hypertrophy, as well as declining blood glucose [54]. Amygdalin increases the proapoptotic Bax protein secretion and declines the anti-apoptotic Bcl-2 protein expression on the breast cancer cell line; therefore, amygdalin is a suitable agent for treating breast cancer [55]. Amygdalin improves the inflammation, oxidative stress, and renal tissue fibrosis of diabetic nephropathy by controlling the key enzymes of matrix degradation [56]. Amygdalin amends chronic mild stress-induced alopecia areata injury in the skin of mice by decreasing the levels of interleukin-6, interleukin-1 $\beta$, tumor necrosis factor- $\alpha$, and osteopontin [57].

\section{Adverse Effects of Semen armeniacae}

Semen armeniacae is used to treat asthma and bronchitis. It is used in the clinic and has few adverse effects. Semen armeniacae facilitates the stereoselective metabolism of its amygdalin ingredient [58]. Decoction of Semen armeniacae to 2275 patients with COVID-19 improves many clinical parameters such as lung state, clinical cure rate, length of hospital stay, a total score of clinical symptoms, fever reduction time, symptom score of fever, number of cough reduction cases, symptom score of cough, number of fatigue reduction cases, symptom score of fatigue, disappearing time of fatigue, viral nucleic acid testing, and inflammatory biomarkers (C-reactive protein) and no severe adverse effects was identified by Semen armeniacae [59]. Oral intake of Semen armeniacae suppressed the inflammatory symptoms in the lung, including increased alveolar wall thickness, accumulation of collagen fibers, and cytokine release. Treatment with Semen armeniacae lowers the levels of inflammatory cells in bronchoalveolar lavage fluid and lung tissue [60]. Semen armeniacae had no mutagenicity in vitro and in vivo. This is in agreement with the clinical safety of Semen armeniacae long-term used in China [61].

\section{Metabolism and Pharmacokinetics of Semen armeniacae}

The intake of $30 \mathrm{mg}$ of amygdalin or prunasin to rats increases their small and large intestines concentrations. In rats, prunasin hydrolysis was higher than that of amygdalin. Prunasin was accumulated in the spleen, large intestine, and kidney $(35 \mu \mathrm{g}, 15 \mu \mathrm{g}$, and $8.9 \mu \mathrm{g}$ 
of prunasin hydrolyze/hour/g of tissue, respectively). The stomach, kidney, spleen, and liver tissue had a more excellent hydrolytic capability than the homogenate of these organs. The oral intake of $30 \mathrm{mg}$ of amygdalin to rats, distribution after the first hour was as follows: stomach $0.89 \mathrm{mg}$, small intestine $0.78 \mathrm{mg}$, spleen $0.36 \mathrm{mg}$, large intestine $0.30 \mathrm{mg}$, kidney $0.19 \mathrm{mg}$, liver $0.10 \mathrm{mg}$, and serum $5.6 \mu \mathrm{g} / \mathrm{ml}$. After 2 hours, the highest amygdalin content, $0.79 \mathrm{mg}$, was found in the large intestine [62,63]. Semen armeniacae contains $\beta$-sitosterol, stigmasterol, and quercetin ingredients that fight COVID-19 [64]. Semen armeniacae intake improved the bioavailability of amygdalin and prunasin ingredients [65].

\section{Toxicology of Semen armeniacae}

Amygdalin's lethal dose (LD50) in rats was $880 \mathrm{mg} / \mathrm{kg}$ bw. Total and magnesium adenosine triphosphatase activities in the heart decreased with increasing levels of amygdalin administeration $[62,63]$. Diets include Semen armeniacae seeds that were fed to young and breeding male and female rats. The growth of young male animals was higher in low amygdalin content in Semen armeniacae seeds groups. These results refer to the animals were more sensitive to the bitter taste of the kernels as a result of high amygdalin content. The rats efficiently excreted thiocyanate, indicating efficient detoxification and clearance of cyanide hydrolyzed from amygdalin in the diet. The blood chemistry was revealed unchanged after amygdalin intake [66].

The intraperitoneal injection of $250 \mathrm{mg} / \mathrm{kg}$ bw, $500 \mathrm{mg} / \mathrm{kg}$ bw, or $750 \mathrm{mg} / \mathrm{kg}$ bw of amygdalin/day to rats for 5 days, the mortality was $30.8 \%, 44.1 \%$, and $56.8 \%$, respectively [67]. The effect of essential oil from Semen armeniacae seeds containing $94 \%$ unsaturated fatty acids and oleic and linoleic acids was evaluated in rats. The rats eat a diet that includes this oil. No toxic effects were observed, and no histopathological changes or lesions were found in any of the body organs [68]. Oral intake of Semen armeniacae extract for 28 days did not cause any hematological, biochemical, or histological changes in rats [48]. Prunus armeniaca plant declines oxidative stress, inflammation, degeneration of fat, and necrosis in alcohol-induced in-vivo and in-vitro liver injury models [69]. The injection with amygdalin (at doses of 0.6 and $3 \mathrm{mg} / \mathrm{kg}$ ) daily for 28 days revealed that amygdalin did not affect bone mineral density, cortical bone thickness, relative bone volume, trabecular number, bone surface, trabecular thickness, trabecular separation [70]. Amygdalin is not genotoxic. It exhibits an antigenotoxic effect against oxidative damaged DNA, and this effect is related to its antioxidant properties on human lymphocytes [71]. There is a rebound metabolic acidosis after massive amygdalin overdose. Therefore, amygdalin efficacy occurs without any adverse effects [72].

\section{Warnings of Semen armeniacae}

The lethal dose equals 7-10 kernels in children and 50-60 kernels (= $30 \mathrm{~g})$ in adults [73]. There are no changes observed in body weight, organ weight, gross features, and histological parameters with $2,000 \mathrm{mg} / \mathrm{kg}$ of Semen armeniacae in both male and female rats [74]. In the single-dose oral toxicity study, the lethal dose is higher than $5000 \mathrm{mg} / \mathrm{kg}$ in rats for Prunus armeniaca plant. The oral dose of the plant at 0, 1250, 2500, and $5000 \mathrm{mg} / \mathrm{kg} / \mathrm{day}$ for 28 in 10 male rats and 10 female rats showed no clinical signs of toxicological significance in any animal during the dosing and the observation period in the single-dose study [75]. 


\section{Precautions of Semen armeniacae}

10.1. Carcinogenesis, mutagenesis, impairment of fertility.

There is no effect on fertility in rats after feeding a diet contains Semen armeniacae for 5 weeks [76]. The Prunus armeniaca seeds water extract without any mutagenic effect in the Salmonella/microsome test using Salmonella typhimurium strains TA98 and TA100, or in the Bacillus subtilis H-17 recombinant test at concentrations up to $100 \mathrm{mg} / \mathrm{ml} \mathrm{[77].} \mathrm{The}$ antigenotoxicity of Semen armeniacae is similar in its effect to that of anise oil [78]. The Prunus armeniaca seeds water extract was mutagenic in the Salmonella/microsome test in Salmonella typhimurium strains TA98 and TA100 at a concentration of $12.5 \mathrm{mg} / \mathrm{plate}$ [79].

\subsection{Pregnancy: teratogenic effects.}

The injection of amygdalin to female pregnant hamsters induced skeletal defects in the offspring and embryopathy effects. The embryopathy effect of amygdalin is due to the release of bacterial $\beta$-glucosidase activity [80]. A pregnant woman who took amygdalin as daily injections during the last trimester gave birth to a live infant at term [81].

\subsection{Pregnancy: non-teratogenic effects.}

The offspring of rats fed a high-amygdalin diet for 18 weeks had minor 3-day survival indices, lactation indices, and weaning weights than those fed the low-amygdalin diet group [76].

\subsection{Other precautions.}

There is no information available on general precautions or precautions concerning drug interactions; or drug and laboratory test interactions.

\section{Dosage of Semen armeniacae}

Semen armeniacae must store in a cool, dry place, protected from moths [3]. The average daily dose $=3-9 \mathrm{~g}$ of Semen armeniacae treated by breaking into pieces, rinsing in boiling water, stir-frying until yellow, and then adding to a decoction when nearly finished [3].

\section{Conclusions}

Semen armeniacae is the seeds of Prunus armeniaca L. (Rosaceae). The Prunus armeniaca contains 3\% amygdalin, titratable acidity, sugars (saccharose, fructose, and glucose), and organic acids (citric and malic acids). Semen armeniacae is used for the treatment of asthma, and cough with expectoration and fever. It is applied for constipation therapy. The pharmacological effect of Semen armeniacae includes experimental and clinical pharmacology. Experimental pharmacology includes anti-cholinesterase, neuroprotective, analgesic, antipyretic, antitumor, antibacterial, antimicrobial, antifungal, and antitussive activities. Prunus armeniaca plant declines oxidative stress, inflammation, degeneration of fat and necrosis in alcohol-induced in-vivo and in-vitro liver injury models. There is no effect on fertility in rats after feeding a diet containing 10\% Semen armeniacae for 5 weeks. The average daily dose $=3-9 \mathrm{~g}$ of Semen armeniacae rinsing in boiling water then adding to a decoction. In 
conclusion, Semen armeniacae has anti-cholinesterase, neuroprotective, analgesic, antipyretic, antitumor, antibacterial, antimicrobial, antifungal, and antitussive activities.

\section{Funding}

This review received no external funding.

\section{Acknowledgments}

This research has no acknowledgment.

\section{Conflict of interest}

The author declares no conflict of interest.

\section{References}

1. Asian pharmacopoeia. Manila, Federation of Asian Pharmaceutical Associations, Asian crude drugs, their preparations and specifications. 1978.

2. The Japanese pharmacopoeia, $13^{\text {th }}$ ed. (English version). Tokyo, Ministry of Health and Welfare, 1996.

3. Pharmacopoeia of the People's Republic of China. Vol. I (English ed.). Beijing, Chemical Industry Press, 2000.

4. Petelot, A. Les plantes médicinales du Camboge, du Laos et du Viêtnam, TomeI. [Medicinal plants in Cambodia, Laos and Viet Nam, Vol. I.] Saigon, Centre de Recherches Scientifi ques et Techniques, 1952.

5. Schlimmer, J.L. Terminologie médico-pharmaceutique et française-persane, $2^{\text {nd }}$ ed. [French-Persian medicopharmaceutical terminology, $2^{\text {nd }}$ ed.] Tehran, University of Tehran Publications, 1970.

6. Medicinal plants in China. Manila, World Health Organization Regional Office for the Western Pacific (WHO Regional Publications, Western Pacific Series, No. 2), 1989.

7. Medicinal plants in the Republic of Korea. Manila, World Health Organization Regional Office for the Western Pacific (WHO Regional Publications Western Pacific Series, No. 21), 1998.

8. Chevalier, A. The encyclopedia of medicinal plants. London, Dorling Kindersley, 1996.

9. Salarbashi ,D.; Jahanbin, K.; Tafaghodi, M.; Fahmideh-Rad, E. Prunus armeniaca gum exudates: An overview on purification, structure, physicochemical properties, and applications. Food Sci Nutr 2021, 9, 1240-1255, http://doi.org/10.1002/fsn3.2107.

10. Gómez-Martínez H, Gil-Muñoz F, Bermejo A, Zuriaga E, Badenes ML. Insights of phenolic pathway in fruits: Transcriptional and metabolic profiling in apricot (Prunus armeniaca). Int J Mol Sci 2021, 22, 3411, http://doi.org/10.3390/ijms22073411.

11. Deng, P.; Cui, B.; Zhu, H.; Phommakoun, B.; Zhang, D.; Li, Y.; Zhao, F.; Zhao, Z. Accumulation pattern of amygdalin and prunasin and its correlation with fruit and kernel agronomic characteristics during apricot (Prunus armeniaca L.) kernel development. Foods 2021, 10, 397, http://doi.org/10.3390/foods10020397.

12. Popović, T.; Menković, J.; Prokić, A.; Obradović, A. First report of xanthomonas arboricola pv. pruni causing leaf and fruit spot on Apricot (Prunus armeniaca L.) in Montenegro. Plant Dis 2021, http://doi.org/10.1094/PDIS-01-21-0161-PDN.

13. Ma, J.X.; Xiao, X.; Zhou, K.F.; Huang, G.; Ao, B.; Zhang, Y.; Gao, W.J.; Lei, T.; Yang, L.; Fan, X.C.; Li, W.H. Herb pair of Ephedrae Herba-Armeniacae Semen Amarum alleviates airway injury in asthmatic rats. $J$ Ethnopharmacol 2021, 269, 113745, http://doi.org/10.1016/j.jep.2020.113745.

14. Ali, S.; Akbar Anjum, M.; Nawaz, A.; Naz, S.; Ejaz, S.; Shahzad Saleem, M.; Tul-Ain Haider, S.; U1 Hasan, M. Effect of gum arabic coating on antioxidative enzyme activities and quality of apricot (Prunus armeniaca L.) fruit during ambient storage. J Food Biochem 2021, 45, e13656, http://doi.org/10.1111/jfbc.13656.

15. Yan, H.; Pengfei, W.; Brennan, H.; Ping, Q.; Bingxiang, L.; Feiyan, Z.; Hongbo, C.; Haijiang, C. Diversity of carotenoid composition, sequestering structures and gene transcription in mature fruits of four Prunus species. Plant Physiol Biochem 2020, 151, 113-123, http://doi.org/10.1016/j.plaphy.2020.03.015.

16. He, L.Y.; Li, B.M. Micro HPLC determination of amygdalin in Semen pruniarmeniacae and Semen prunipersicae. Biomed Chromatogr 1988, 2, 271-273, http://doi.org/10.1002/bmc.1130020609. 
17. Aubert, C.; Chanforan, C. Postharvest changes in physicochemical properties and volatile constituents of apricot (Prunus armeniaca L.). Characterization of 28 Cultivars. J Agric Food Chem 2007, 55, 3074-82, http://doi.org/10.1021/jf063476w.

18. Rashid, F.; Ahmed, R.; Mahmood, A.; Ahmad, Z.; Bibi, N.; Kazmi, S.U. Flavonoid glycosides from Prunus armeniaca and the antibacterial activity of a crude extract. Arch Pharm Res 2007, 30, 932-7, http://doi.org/10.1007/BF02993959.

19. Pintea, A.; Dulf, F.V.; Bunea, A.; Socaci, S.A.; Pop, E.A.; Opriță, V.A.; Giuffrida, D.; Cacciola, F.; Bartolomeo, G.; Mondello, L. Carotenoids, fatty acids, and volatile compounds in apricot cultivars from Romania-A chemometric approach. Antioxidants (Basel) 2020, 9, 562, http://doi.org/10.3390/antiox9070562.

20. Zhou, W.; Niu, Y.; Ding, X.; Zhao, S.; Li, Y.; Fan, G.; Zhang, S.; Liao, K. Analysis of carotenoid content and diversity in apricots (Prunus armeniaca L.) grown in China. Food Chem 2020, 330, 127223, http://doi.org/10.1016/j.foodchem.2020.127223.

21. Gao, J.J.; Jin, C.Q. [Comparison of glucoside content of bitter apricot seeds processed in different ways and stored routinely for one year.] Zhongguo Zhongyao Zazhi 1992, 17, 658-659.

22. Hrichi, S.; Rigano, F.; Chaabane-Banaoues, R.; Oulad El Majdoub, Y.; Mangraviti, D.; Di Marco, D.; Babba, H.; Dugo, P.; Mondello, L.; Mighri, Z.; Cacciola, F. Identification of Fatty Acid, Lipid and Polyphenol Compounds from Prunus armeniaca L. Kernel Extracts. Foods 2020, 9, 896, http://doi.org/10.3390/foods9070896.

23. Su, C.; Zheng, X.; Zhang, D.; Chen, Y.; Xiao, J.; He, Y.; He, J.; Wang, B.; Shi, X. Investigation of sugars, organic acids, phenolic compounds, antioxidant activity and the aroma fingerprint of small white apricots grown in Xinjiang. J Food Sci 2020, 85, 4300-4311, http://doi.org/10.1111/1750-3841.15523.

24. Ahmed, M.S.; Honda, G.; Miki, W. Herb drugs and herbalists in the Middle East. Tokyo, Institute for the Study of Languages and Cultures of Asia and Africa, Tokyo University for Foreign Studies, 1979.

25. Vahedi-Mazdabadi, Y.; Karimpour-Razkenari, E.; Akbarzadeh, T.; Lotfian, H.; Toushih, M.; Roshanravan, N.; Saeedi, M.; Ostadrahimi, A. Anti-cholinesterase and Neuroprotective Activities of Sweet and Bitter Apricot Kernels (Prunus armeniaca L.). Iran J Pharm Res 2020, 19, 216-224, http://doi.org/10.22037/ijpr.2019.15514.13139.

26. Lara, M.V.; Bonghi, C.; Famiani, F.; Vizzotto, G.; Walker, R.P.; Drincovich, M.F. Stone fruit as biofactories of phytochemicals with potential roles in human nutrition and health. Front Plant Sci 2020 11, 562252, http://doi.org/10.3389/fpls.2020.562252.

27. Sun, L.; Mao, M.; Yan, Z.; Zuo, C.; Zhang, X. A Chinese Traditional therapy for bleomycin-induced pulmonary fibrosis in mice. Can Respir J 2018, 2018, 8491487, http://doi.org/10.1155/2018/8491487.

28. Liu, Z.L.; Xie, L.Z.; Zhu, J.; Li, G.Q.; Grant, S.J.; Liu, J.P. Herbal medicines for fatty liver diseases. Cochrane Database Syst Rev 2013, 8, CD009059, http://doi.org/10.1002/14651858.CD009059.pub2.

29. Bonesi, M.; Tenuta, M.C.; Loizzo, M.R.; Sicari, V.; Tundis, R. Potential application of Prunus armeniaca L. and P. domestica L. leaf essential oils as antioxidant and of cholinesterases inhibitors. Antioxidants (Basel) 2018, 8, 2, http://doi.org/10.3390/antiox8010002.

30. Dhar, P.; Das, S.K.; Barhwal, K.; Hota, S.K.; Mishra, K.P.; Singh, S.B. Trans-Himalayan phytococktail confers protection against hypobaric hypoxia-induced hippocampal neurodegeneration and memory impairment in male sprague dawley rats. High Alt Med Biol 2019, 20, 279-292, http://doi.org/10.1089/ham.2019.0011.

31. Yuan, D.; Komatsu, K.; Cui, Z.; Kano,Y. Pharmacological properties of traditional medicines. XXV. Effects of ephedrine, amygdalin, glycyrrhizin, gypsum and their combinations on body temperature and body fluid. Biol Pharm Bull 1999, 22, 165-171, http://doi.org/10.1248/bpb.22.165.

32. Zhu, Y.P.; Su, Z.W.; Li, C.H. [Analgesic effect and no physical dependence of amygdalin]. Zhongguo Zhong Yao Za Zhi. 1994, 19, 105-107.

33. Koriem, K.M.M.; Gad, I.B.; Nasiry, Z.K. Protective effect of Cupressus sempervirens extract against indomethacin-induced gastric ulcer in rats. Interdiscip Toxicol 2015, 8, 25-34, https://doi.org/10.1515/intox2015-0006.

34. Hwang, H.J.; Kim, P.; Kim, C.J.; Lee, H.J.; Shim, I.; Yin, C.S.; Yang, Y.; Hahm, D,H. Anti-nociceptive effect of amygdalin isolated from Prunus armeniaca on formalin-induced pain in rats. Biol Pharm Bull 2008, 31, 1559-64, http://doi.org/10.1248/bpb.31.1559.

35. Jena, A.K.; Vasisht, K.; Sharma, N.; Kaur, R.; Dhingra, M.S.; Karan, M. Amelioration of testosterone induced benign prostatic hyperplasia by Prunus species. $J$ Ethnopharmacol 2016, 190, 33-45, http://doi.org/10.1016/j.jep.2016.05.052. 
36. Chitnis, M.P.; Adwankar, M.K.; Amonkar, A.J. Studies on high-dose chemotherapy of amygdalin in murine P388 lymphocytic leukaemia and P815 mast cell leukaemia. J Cancer Res Clin Oncol 1985, 109, 208-209, http://doi.org/10.1007/BF00390359.

37. Toygar, İ.; Yeşilbalkan, Ö.U.; Kürkütlü, M.; Aslan, A. Complementary and alternative medicines used by cancer patients to cope with chemotherapy-induced constipation. Complement Ther Clin Pract 2020, 39, 101108, http://doi.org/10.1016/j.ctcp.2020.101108.

38. Saleem, M.; Asif, J.; Asif, M.; Saleem, U. Amygdalin from apricot kernels induces apoptosis and causes cell cycle arrest in cancer cells: An updated review. Anticancer Agents Med Chem 2018, 18, 1650-1655, http://doi.org/10.2174/1871520618666180105161136.

39. Aamazadeh, F.;Ostadrahimi, A.; Rahbar Saadat, Y.; Barar, J. Bitter apricot ethanolic extract induces apoptosis through increasing expression of Bax/Bcl-2 ratio and caspase-3 in PANC-1 pancreatic cancer cells. Mol Biol Rep 2020, 47, 1895-1904, http://doi.org/10.1007/s11033-020-05286-w.

40. Wang, D.; Dong, Y.; Chen, X.; Liu, Y.; Wang, J.; Wang, X.; Wang, C.; Song, H. Incorporation of apricot (Prunus armeniaca) kernel essential oil into chitosan films displaying antimicrobial effect against Listeria monocytogenes and improving quality indices of spiced beef. Int J Biol Macromol 2020, 162, 838-844, http://doi.org/10.1016/j.ijbiomac.2020.06.220.

41. Shaheen, N.; Qureshi, N.A.; Ashraf, A.; Hamid, A.; Iqbal, A.; Fatima, H. In vitro anti-leishmanial activity of Prunus armeniaca fractions on Leishmania tropica and molecular docking studies. J Photochem Photobiol B 2020, 213, 112077, http://doi.org/10.1016/j.jphotobiol.2020.112077.

42. Nafis, A.; Kasrati, A.; Jamali, C.A.; Custódio, L.; Vitalini, S.; Iriti, M.; Hassani, L. A comparative study of the in vitro antimicrobial and synergistic effect of essential oils from Laurus nobilis L. and Prunus armeniaca L. from Morocco with antimicrobial drugs: New approach for health promoting products. Antibiotics (Basel) 2020, 9, 140, http://doi.org/10.3390/antibiotics9040140.

43. Kinoti, W.M.; Nancarrow, N.; Dann, A.; Rodoni, B.C.; Constable, F.E. Updating the quarantine status of Prunus infecting viruses in Australia. Viruses 2020, 12, 246, http://doi.org/10.3390/v12020246.

44. Iličić, R.; Popović, T. Occurrence of bacterial spot caused by Xanthomonas arboricola pv. pruni on peach and apricot in Serbia. Plant Dis 2020, 105, http://doi.org/10.1094/PDIS-08-20-1817-PDN.

45. Dumin, W.; Park, M.J.; Park, J.H.; Yang, C.Y.; Back, C.G. First report of bacterial shot-hole disease caused by Xanthomonas arboricola pv. pruni on plumcot in South Korea. Plant Dis 2020, 105, http://doi.org/10.1094/PDIS-06-20-1227-PDN.

46. Koh, K.H.; Tham, F.Y. Screening of traditional Chinese medicinal plants for quorum-sensing inhibitors activity. J Microbiol Immunol Infect 2011, 44, 144-148, https://doi.org/10.1016/j.jmii.2009.10.001.

47. Miyagoshi, M.; Amagaya, S.; Ogihara, Y. Antitussive effects of L-ephedrine, amygdalin, and makyokansekito (Chinese traditional medicine) using a cough model induced by sulfur dioxide gas in mice. Planta Med 1986, 4, 275-278, http://doi.org/10.1055/s-2007-969151.

48. Huang, K.C. The pharmacology of Chinese herbs. Boca Raton, FL, CRC Press, 1993, https://doi.org/10.1111/j.2042-7158.1994.tb03767.x.

49. Lin, Y.C.; Chang, C.W.; Wu, C.R. Antitussive, antipyretic and toxicological evaluation of Ma-Xing-GanShi-Tang in rodents. BMC Complement Altern Med 2016, 16, 456, http://doi.org/10.1186/s12906-016-14402.

50. Yun, J.M.; Im, S.B.; Roh, M.K.; Park, S.H.; Kwon, H.A.; Lee, J.Y.; Choi, H.Y.; Ham, I.H.; Kim, Y.B.; Lee, J.M.; Kim, D.O.; Park, K.W.; Kang, H. Prunus yedoensis bark inhibits lipopolysaccharide-induced inflammatory cytokine synthesis by IkappaBalpha degradation and MAPK activation in macrophages. J Med Food 2014, 17, 407-13, http://doi.org/10.1089/jmf.2013.2825.

51. Hosny, S.; Sahyon, H.; Youssef, M.; Negm, A. Prunus armeniaca L. seed extract and its amygdalin containing fraction induced mitochondrial-mediated apoptosis and autophagy in liver carcinogenesis. Anticancer Agents Med Chem 2021, 21, 621-629, http://doi.org/10.2174/1871520620666200608124003.

52. Tř́sková, A,; Rudá-Kučerová, J. Can amygdalin provide any benefit in integrative anticancer treatment?. Klin Onkol 2019, 32, 360-366, http://doi.org/10.14735/amko2019360.

53. Shi, J.;Chen, Q.; Xu, M.; Xia, Q.; Zheng, T.; Teng, J.; Li, M.; Fan, L. Recent updates and future perspectives about amygdalin as a potential anticancer agent: A review. Cancer Med 2019, 8, 3004-3011, http://doi.org/10.1002/cam4.2197.

54. He, X.Y.; Wu, L.J.; Wang, W.X.; Xie, P.J.; Chen, Y.H.; Wang, F. Amygdalin - A pharmacological and toxicological review. J Ethnopharmacol 2020, 254, 112717, http://doi.org/10.1016/j.jep.2020.112717. 
55. Moradipoodeh, B.; Jamalan, M.; Zeinali, M.; Fereidoonnezhad, M.; Mohammadzadeh, G. In vitro and in silico anticancer activity of amygdalin on the SK-BR-3 human breast cancer cell line. Mol Biol Rep 2019, 46, 6361-6370, http://doi.org/10.1007/s11033-019-05080-3.

56. Chen, J.; Hu, Y.; Mou, X.; Wang, H.; Xie, Z. Amygdalin alleviates renal injury by suppressing inflammation, oxidative stress and fibrosis in streptozotocin-induced diabetic rats. Life Sci 2021, 265, 118835, http://doi.org/10.1016/j.lfs.2020.118835.

57. He, X.; Duan, X.; Liu, J.; Sha, X.; Gong, Y.; Lu, W.; Li, Z.; Chen, X.; Li, Y.; Shen, Z. The anti-inflammatory effects of Xuefu Zhuyu decoction on $\mathrm{C} 3 \mathrm{H} / \mathrm{HeJ}$ mice with alopecia areata. Phytomedicine 2021, 81, 153423, http://doi.org/10.1016/j.phymed.2020.153423.

58. Song, S.; Ma, Q.; Tang, Q.; Chen, F.; Xing, X.; Guo, Y.; Guo, S.; Tan, X.; Luo, J. Stereoselective metabolism of amygdalin-based study of detoxification of Semen armeniacae Amarum in the Herba Ephedrae-Semen armeniacae Amarum herb pair. $J$ Ethnopharmacol 2016, 179, 356-66, http://doi.org/10.1016/j.jep.2015.12.019.

59. Xiong, X.; Wang, P.; Su, K.; Cho, W.C.; Xing, Y. Chinese herbal medicine for coronavirus disease 2019: A systematic review and meta-analysis. Pharmacol Res 2020, 160, 105056, http://doi.org/10.1016/j.phrs.2020.105056.

60. Yang, W.K.; Lyu, Y.R.; Kim, S.H.; Chae, S.W.; Kim, K.M.; Jung, I.C.; Park, Y.C. Protective effect of GHX02 extract on particulate matter-induced lung injury. J Med Food 2020, 23, 611-632, http://doi.org/10.1089/jmf.2019.4568.

61. Jin, J.; Liu, B.; Zhang, H.; Tian, X.; Cai, Y.; Gao, P. Mutagenicity of chinese traditional medicine Semen armeniacae amarum by two modified Ames tests. BMC Complement Altern Med 2009, 9, 43, http://doi.org/10.1186/1472-6882-9-43.

62. Adewusi, S.R.; Oke, O.L. On the metabolism of amygdalin. 1 . The $\mathrm{LD}_{50}$ and biochemical changes in rats. Can J Physiol Pharmacol 1985, 63, 1080-1083, http://doi.org/10.1139/y85-177.

63. Adewusi, S.R.; Oke, O.L. On the metabolism of amygdalin. 2. The distribution of beta-glucosidase activity and orally administered amygdalin in rats. Can J Physiol Pharmacol 1985, 63, 1084-1087, http://doi.org/10.1139/y85-178.

64. Luo, L.; Jiang, J.; Wang, C.; Fitzgerald, M.; Hu, W.; Zhou, Y.; Zhang, H.; Chen, S. Analysis on herbal medicines utilized for treatment of COVID-19. Acta Pharm Sin B 2020, 10, 1192-1204, http://doi.org/10.1016/j.apsb.2020.05.007.

65. Song, S.; Chen, F.; Xing, X.; Ren, M.; Ma, Q.; Xie, Y.; Tang, Q.; Luo, J. Concurrent quantification and comparative pharmacokinetic analysis of bioactive compounds in the Herba Ephedrae-Semen armeniacae Amarum herb pair. J Pharm Biomed Anal 2015, 109, 67-73, http://doi.org/10.1016/j.jpba.2015.02.004.

66. Miller, K.W.; Anderson, J.L.; Stoewsand, G.S. Amygdalin metabolism and effect on reproduction of rats fed apricot kernels. J Toxicol Environ Health 1981, 7, 457-467, http://doi.org/10.1080/15287398109529994.

67. Khandekar, J.D.; Edelman, H. Studies of amygdalin (laetrile) toxicity in rodents. JAMA 1979, 242, 169-171.

68. Gandhi, V.M.; Mulky, M.J.; Mukerji, B.; Iyer, V.J.; Cherian, K.M. Safety evaluation of wild apricot oil. Food Chem Toxicol 1997, 35, 583-587, http://doi.org/10.1016/s0278-6915(97)00026-4.

69. Singh, M.; Hussain, T.; Firdous, H.; Shaikh, S.; Rizvi, S.M.D.; Moin, A.; Khan, M.; Kamal, M.A. Preclinical hepatoprotective effect of herbalism against ethanol induced hepatotoxicity: A review. Curr Drug Metab 2018, 19, 1002-1011, http://doi.org/10.2174/1389200219666180330125003.

70. Kovacova, V.; Sarocka, A.; Omelka, R.; Bauerova, M.; Grosskopf, B.; Formicki, G.; Kolesarova, A.; Martiniakova, M. Subacute exposure to amygdalin influences compact bone remodeling of rabbits. $J$ Physiol Pharmacol 2019, 70, http://doi.org/10.26402/jpp.2019.4.15.

71. Erikel, E.; Yuzbasioglu, D.; Unal, F. Genotoxic and antigenotoxic potential of amygdalin on isolated human lymphocytes by the comet assay. J Food Biochem 2020, 44, e13436, http://doi.org/10.1111/jfbc.13436.

72. Shively, R.M.; Harding, S.A.; Hoffman, R.S.; Hill, A.D.; Astua, A.J.; Manini, A.F. Rebound metabolic acidosis following intentional amygdalin supplement overdose. Clin Toxicol (Phila) 2020, 58, 290-293, http://doi.org/10.1080/15563650.2019.1640369.

73. McGuffin, M. eds. Botanical safety handbook, Boca Raton, FL, CRC Press, 1997.

74. Park, J.H.; Seo, B.I.; Cho, S.Y.; Park, K.R.; Choi, S.H.; Han, C.K.; Song, C.H.; Park, S.J.; Ku, S.K. Single oral dose toxicity study of prebrewed armeniacae semen in rats. Toxicol Res 2013, 29, 91-98, http://doi.org/10.5487/TR.2013.29.2.091. 
75. Ji, K.Y.; Kim, K.M.; Oh, J.J.; Kim, J.W.; Lee, W.J.; Cho, H.; Lee, H.K.; Lee, J.Y.; Chae, S. Assessment of the 4-week repeated-dose oral toxicity and genotoxicity of GHX02. J Appl Toxicol 2020, 40, 270-284, http://doi.org/10.1002/jat.3902.

76. Miller, K.W.; Anderson, J.L.; Stoewsand, G.S. Amygdalin metabolism and effect on reproduction of rats fed apricot kernels. J Toxicol Environl Health 1981, 7, 457-467, http://doi.org/10.1080/15287398109529994.

77. Morimoto, I.; Watanabe, F.; Osawa, T.; Okitsu, T.; Kada, T. Mutagenicity screening of crude drugs with Bacillus subtilis rec-assay and Salmonella/microsome reversion assay. Mutat Res 1982, 97, 81-102, http://doi.org/10.1016/0165-1161(82)90007-3.

78. Koriem, K.M.M.; Arbid, M.S.; El-Gendy, N.F. The protective role of anise oil in oxidative stress and genotoxicity produced in favism. J Diet Suppl 2016, 13, 505-521, https://doi.org/10.3109/19390211.2015.1119775.

79. Yamamoto, H.; Mizutani, T.; Nomura, H. [Studies on the mutagenicity of crude drug extracts. I.] Yakugaku Zasshi 1982, 102, 596-601, http://doi.org/10.1248/yakushi1947.102.6_596.

80. Willhite, C.C. Congenital malformations induced by laetrile. Science 1982, 215, 1513-1515, http://doi.org/10.1126/science.7063858.

81. Peterson, R.G.; Rumack, B.H. Laetrile and pregnancy. Clin Toxicol 1979, 15, 181-184, http://doi.org/10.3109/15563657908989863. 